\title{
OPTIMALISASI DESAIN DAN POSISI JIG WELDING GUNA MENGURANGI SPATTER PADA PRODUKSI HALF OUTER COMP MENGGUNAKAN METODE DMAIC di PT. XYZ
}

\author{
Zulkani Sinaga ${ }^{1}$, Achmad Muhazir ${ }^{2}$, Muhamad Ilham Fuadi ${ }^{3}$ \\ ${ }^{1}$ Program Studi Teknik Industri, Universitas Bhayangkara Jakarta Raya, Jl. Perjuangan, Bekas \\ E-mail : sng.zulkani@gmail.com, achmad.muhazir@ubharajaya.ac.id ilhamfuadi69@gmail.com
}

\begin{abstract}
Abstrak
Penelitian ini dilakukan pada salah satu produsen spare part otomotif PT. XYZ memiliki permasalahan dan menjadi perhatian serius pada bagian pengelasan adanya produk cacat yang dapat menurunkan nilai dan kualitas produk sehingga banyak produk yang ditolak oleh konsumen karena tidak sesuai dengan standar, dimana banyak terdapat kotoran las (Spatter) yang menmpel pada Joint Exhaust produk Half Outer Comp merupakan bagian komponen dari knalpot sehingga mengurangi produktifitas produksi pada bagian inspeksi akhir, permasalahan di atas dianggap perlu dilakukan penelitian untuk mencari penyebab hal tersebut. Beberapa langkah dilakukan guna memperbaiki cacat yang ada yaitu langkah awal dilakukan observasi dan wawancara ke bagian produksi, metode yang digunakan untuk pengolahan data hasil observasi menggunakan metode DMAIC (Define, Measure, Analisys, Improve, Control), kemudian dilakukan optimalisasi dan modifikasi Jig Welding dengan mendesain ulang menggunakan perangkat software Solidwork versi 2018, kemudian mengubah posisi Jig sebelumnya vertikal menjadi horizontal agar supaya pada saat pengelasan Spatter tidak langsung jatuh ke Joint Exhaust dan memberikan penahan tambahan pada Jig guna mengurangi jumlah Spatter menempel pada Half Outer Comp. Pada penelitian ini diperoleh hasil dimana jumlah Spatter yang menempel pada Joint Exhaust sangat berkurang dan memperoleh hasil produk yang lebih baik sehingga meningkatkan produktivitas pada bagian inspeksi akhir sebelumnya 58,33\% menjadi sebesar $83.33 \%$.
\end{abstract}

Kata Kunci : Optimalisasi, Spatter, DMAIC, Desain, Solidwork 2018

\begin{abstract}
This research was conducted at one of the automotive spare part manufacturers PT. XYZ has a problem and is a serious concern on the welding part of the presence of defective products that can reduce the value and quality of the product so that many products are rejected by consumers because it does not comply with standards, where there is a lot of welding dirt (Spatter) which attaches to the Joint Exhaust Half Outer Comp product is a component of the muffler so as to reduce production productivity at the final inspection, the above problems are considered necessary to do research to find the cause of it. Several steps were taken to correct existing defects, namely the initial steps carried out observation and interviews to the production department, the method used for processing the observation data using the DMAIC method (Define, Measure, Analysis, Improve, Control), then optimization and modification of Jig Welding with redesign using the 2018 Solidwork software tool, then changing the position of the previous vertical jig to horizontal so that when welding Spatter does not directly fall into the Joint Exhaust and provide additional support to the Jig to reduce the number of Spatter attached to the Half Outer Comp. In this study the results obtained where the number of Spatter attached to the Joint Exhaust is greatly reduced and obtain better product results thereby increasing productivity in the previous final inspection section of $58.33 \%$ to $83.33 \%$.
\end{abstract}

Keywords : Optimization, Spatter, DMAIC, Design, Solidwork 2018

\section{PENDAHULUAN}

Produk cacat (defect) merupakan cacat atau kekurangan yang dapat menyebabkan turunnya nilai atau kualitas dari suatu produk sehingga barang atau jasa yang dihasilkan menjadi tidak maksimal dan itu akan mengurangi keuntungan perusahaan jika defect ini tidak ditangani dengan baik, karena akan banyak produk yang ditolak atau tidak diterimanya produk oleh pelanggan sehingga produk tersebut tidak dapat dijual. PT. XYZ adalah perusahaan yang bergerak di bidang manufaktur dimana perusahaan ini memproduksi komponen knalpot 
kendaraan bermotor roda dua, salah satunya yaitu half outer comp atau yang biasa dikenal dengan sebutan header knalpot yang berfungsi sebagai penyalur gas buang dari mesin bakar ke dalam knalpot untuk kemudian disalurkan menjadi gas buang melalui lubang pembuangan knalpot.

Pada proses welding (pengelasan) half outer comp didapatkan adanya spatter (kotoran las) pada bagian joint exhaust, banyaknya spatter yang menempel membuat kualitas dari half outer comp tidak sesuai standar keinginan pelanggan, sehingga produk tersebut tidak dapat dikirim atau dijual dan agar dapat bisa terjual spatter harus dibersihkan terlebih dahulu yang mengakibatkan penambahan proses kerja dibagian check man sehingga jumlah produk yang di cek menurun.

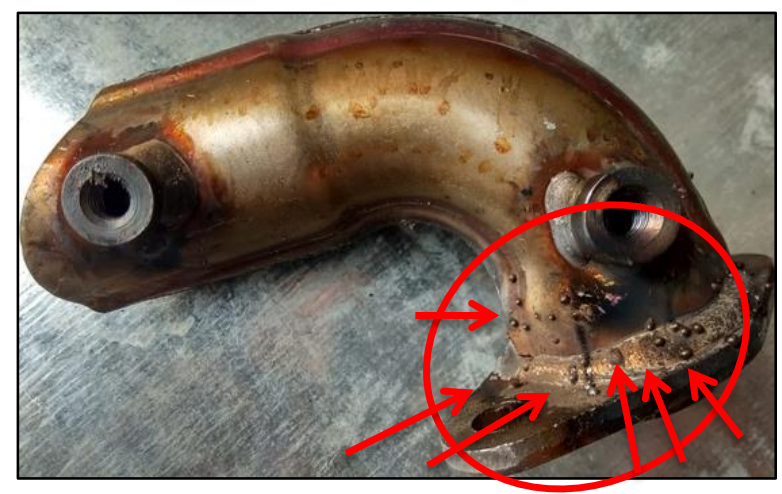

Gambar 1.1 Spatter Pada Joint Exhaust

Di bawah ini adalah data kecacatan (defect) dan diagram pareto chart dari hasil produksi half outer comp, yang berguna untuk mengurutkan jenis kecacatan yang tertinggi.

Tabel 1.1 Data Defect dalam satu Shift

\begin{tabular}{|c|c|c|c|c|}
\hline No & Jenis kecacatan & $\begin{array}{c}\text { Hasil Produksi } \\
\text { (pcs) }\end{array}$ & $\begin{array}{c}\text { Jumlah } \\
\text { Cacat (pcs) }\end{array}$ & Persentasi (\%) \\
\hline 1 & Welding Undercut & 300 & 10 & $3 \%$ \\
\hline 2 & Welding Bocor & 300 & 24 & $8 \%$ \\
\hline 3 & Tidak Masuk Jig & 300 & 12 & $4 \%$ \\
\hline 4 & Banyak Spatter & 300 & 300 & $100 \%$ \\
\hline
\end{tabular}

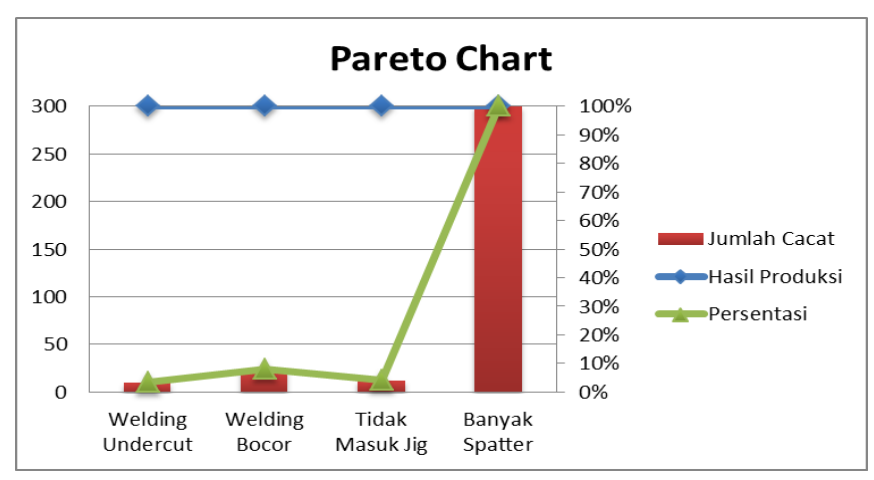

Gambar 1.2 Diagram Pareto Jumlah Cacat Half Outer Comp

Melakukan modifikasi jig welding pada proses produksi welding half outer comp adalah salah satu cara guna mengurangi jumlah spatter (kotoran las) pada produk half outer comp, selain mengutamakan kualitas produk half outer comp yang terbebas dari spatter, hasil dari 
modifikasi jig welding ini juga akan mempermudah bagian pengecekan akhir agar tidak melakukukan pengetrikan atau menghilangkan spatter yang menempel pada half outer comp sehingga dapat mempermudah kinerja para check man dan hasil pengecekan produk half outer comp dapat meningkat.

Permasalahan dalam penelitian ini adalah, sebagai berikut: 1). Banyaknya spatter yang menempel pada half outer comp karena posisi jig welding yang kurang tepat, sehingga terjadi hambatan proses pada bagian check man (pengecekan akhir) karena harus menghilangkan banyaknya spatter (kotoran las) pada half outer comp dengan cara diketrik sehingga produktivitas menurun. 2). Terjadinya permasalahan kualitas pada produk half outer comp karena banyaknya spatter (kotoran las) yang menempel pada joint exhaust.

Batasan dari penelitian ini adalah: 1). melakukan penelitian bagaimana cara menghilangkan atau mengurangi jumlah spatter yang menempel pada half outer comp dengan melakukan improve dan modifikasi pada jig welding half outer comp. 2). memberikan gambaran dari jig welding dengan posisi penempatan yang berbeda sebagai usulan guna menghilangkan jenis cacat banyak spatter pada joint exhaust.

Tujuan dari penelitian ini adalah: 1). Mengetahui penyebab terjadinya spatter (kotoran las) yang menempel pada proses produksi half outer comp. 2). Melakukan perbaikan pada proses produksi half outer comp dengan melakukan modifikasi jig welding pada proses produksi welding half outer comp untuk mengurangi jumlah spatter yang menempel pada half outer comp menggunakan metode DMAIC (Define, Measure, Improve dan Control).

\section{TINJAUAN PUSTAKA}

\section{Define (Definisi)}

Pada tahap ini akan menyajikan urutan proses produksi half outer comp dan menentukan kunci yang banyak mengakibatkan defect dan pengaruh terhadap critical to quality serta didefinisikan masalah yang terjadi dan kemungkinan untuk dilakukan perbaikan. 2. Measure (Pengkuran)

Beberapa hal yang dilakukan dalam tahap ini yaitu menentukan cacat dominan yang merupakan critical to quality dengan menggunakan diagram pareto sebagai alat untuk mengidentifikasinya.

3. Analysis (Analisis)

Pada tahap ini dilakukan penetapan akar penyebab masalah yang dilakukan menggunakan diagram fish bone melalui pandangan beberapa faktor yaitu operator, mesin, tools, metode, Dengan fish bone diagram akan lebih mempermudah proses analisa permasalahan. Setelah itu dianalisa untuk mendapatkan akar penyebab dari kecacatan.

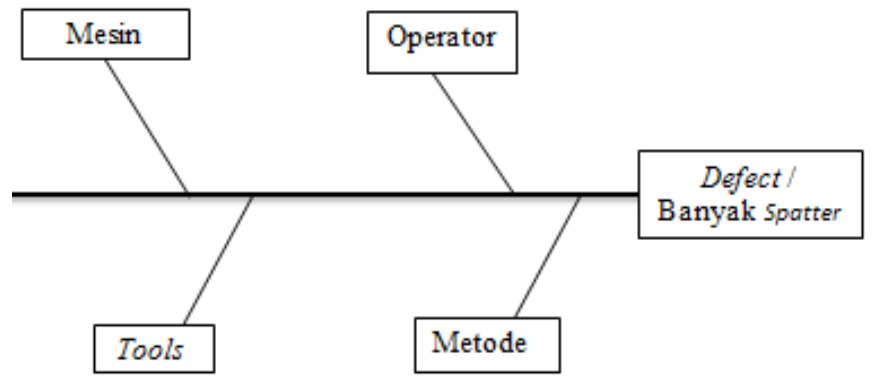

Gambar 2.1 Diagram Fish Bone 


\section{Tahap Improve (Perbaikan)}

Pada tahap ini dilakukan perbaikan yang didapatkan dari hasil pengamatan dan analisa pada proses produksi half outer comp dan melakukan berbagai upaya untuk mengeliminasi berbagai penyebab cacat produk, setelah masalah teridentifikasi lalu dilakukan perbaikan.

5. Tahap Control (Pengawasan)

Bila implementasi telah dilaksanakan dan terlihat perbaikan hasilnya, dilakukan tahapan kontrol atau pengawasan yang mana juga dilakukan analisa pada data dan proses untuk mengetahui perbandingan antara proses lama dengan proses yang telah mengalami perbaikan.

\section{METODOLOGI}

Penelitian ini dilakukan pada proses produksi half outer comp dibagian proses robot welding di PT. XYZ. Pengumpulan data primer dilakukan dengan cara seperti observasi lapangan dan wawancara dengan para karyawan di PT. XYZ. Sedangkan data sekunder diperoleh dari berbagai pustaka dan dokumen yang terkait penelitian. Metode tanya jawab dilakukan dengan cara memberikan suatu pertanyaan yang berhubungan dengan permasalahan yang sedang diteliti, di bawah ini adalah beberapa responden dalam penelitian ini.

Tabel 2.1 Responden Penelitian :

\begin{tabular}{|c|l|l|}
\hline No. & \multicolumn{1}{|c|}{ Narasumber } & \multicolumn{1}{c|}{ Responden } \\
\hline 1. & Karyawan & $\begin{array}{l}1 \text { orang operator robot welding di shift 1 } \\
1 \text { orang operator robot welding di shift 2 } \\
1 \text { orang operator robot welding di shift 3 }\end{array}$ \\
\hline 2. & Karyawan & 1 orang leader produksi bagian welding \\
\hline
\end{tabular}

Data hasil observasi dan wawancara tersebut di analisa menggunakan metode DMAIC. Tahap selanjutnya melakukan perancangan ulang terhadap Jig Welding menggunakan perangkat software Solidwork versi 2018, pemasangan Jig dilakukan pada posisi horizontal untuk menghindari Spatter tidak jatuh langsung mengenai Joint Exhaust. Perancangan dilanjutkan dengan membuat penahan tambahan dan Clamp Jig dengan tujuan mengurangi jumlah Spatter.

\section{HASIL DAN PEMBAHASAN}

Spatter (kotoran las) yang menempel pada joint exhaust half outer comp yaitu terjadi pada proses pemasangan nut, dimana jig yang digunakan memiliki posisi yang sangat memungkinkan spatter menempel pada bagian joint exhaust, dikarenakan posisi penempatan berposisi tegak, dengan proses welding memiliki alur proses dari atas ke bawah yang membuat spatter berjatuhan ke bawah dan menempel pada joint exhaust, serta ditambah lagi dengan kondisi clamp jig (pengunci) yang digunakan untuk mencengkram dan melindungi joint exhaust juga sudah tipis dan sudah tidak menutup dengan sempurna. 

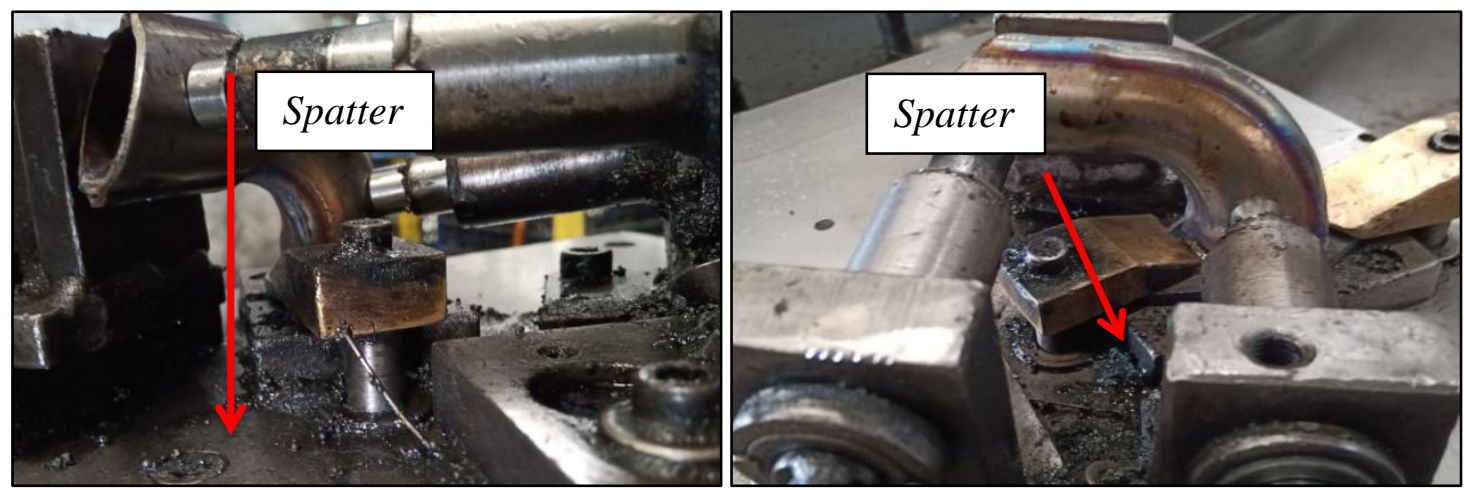

Gambar 4.1 Posisi Jatuhnya Spatter

Membuat suatu penahan atau penghalang agar spatter (kotoran las) tidak jatuh langsung kebagian joint exhaust, dibawah ini adalah beberapa langkah dalam pembuatan penahan spatter (kotoran las). Dari hasil improve di atas disimpulkan bahwa spatter (kotoran las) menempel pada joint exhaust karena posisi jig welding yang berposisi tegak, maka penulis memberikan saran untuk melakukan redesign jig welding dari posisi penempatan vertikal menjadi posisi penempatan berposisi horizontal.

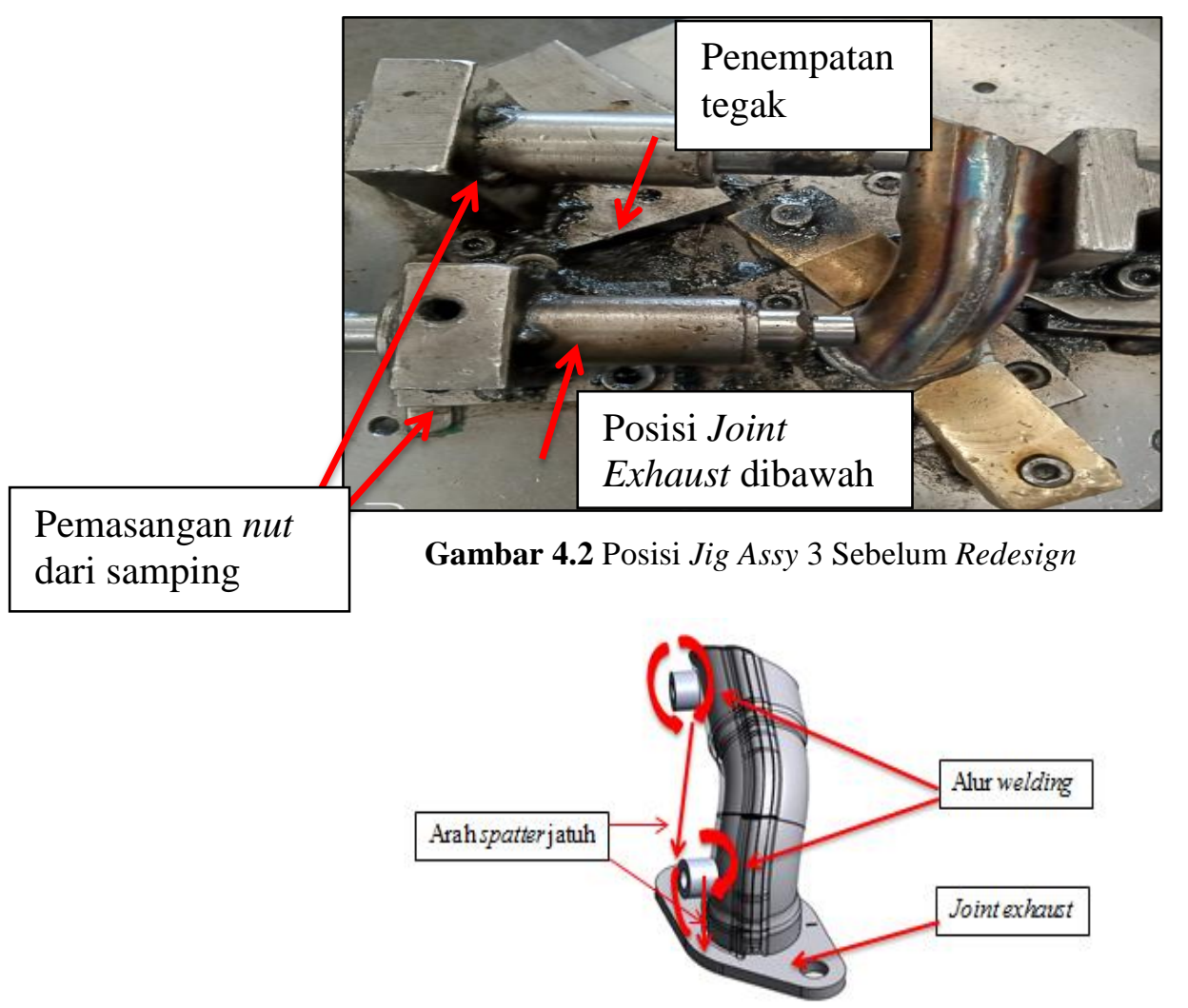

Gambar 4.3 Posisi Jatuhnya Spatter Pada Posisi Jig Welding Vertikal

Dari penjelasan di atas maka penulis melakukan modifikasi perubahan posisi penempatan half outer comp dari posisi vertikal menjadi posisi penempatan horizontal seperti pada gambar di bawah ini. 


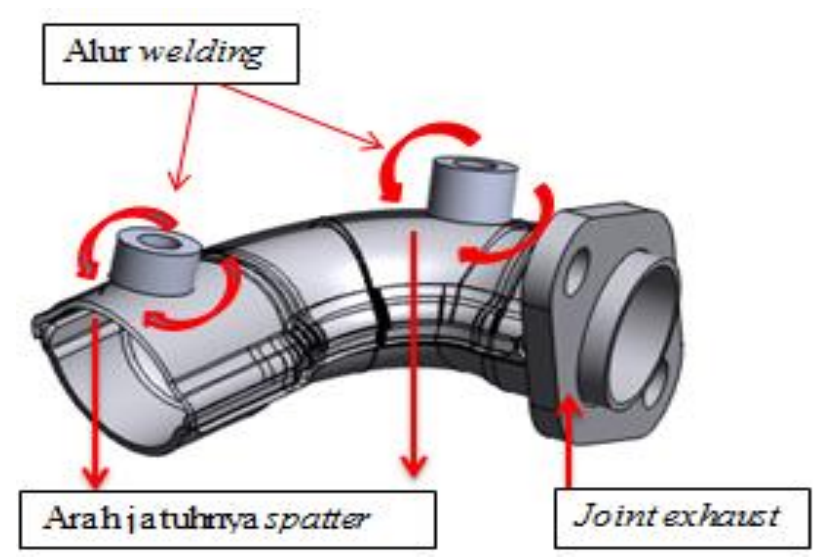

Gambar 4.4 Gambaran Jatuhnya Spatter Posisi Rebah

Pada gambar di atas menunjukan penempatan half outer comp dengan posisi rebah, dimana dalam posisi seperti itu dapat meminimalisir jatuhnya spatter (kotoran las) dan menempel pada joint exhaust saat proses pengelasan berlangsung karena posisi joint exhaust berada di bagian samping.

Dari penjelasan mengenai posisi jig welding dengan penempatan berposisi rebah di atas, maka penulis membuat sebuah usulan design jig welding assy 3 half outer comp rebah dengan menggunaan software solidwork 2018 seperti pada gambar di bawah ini.
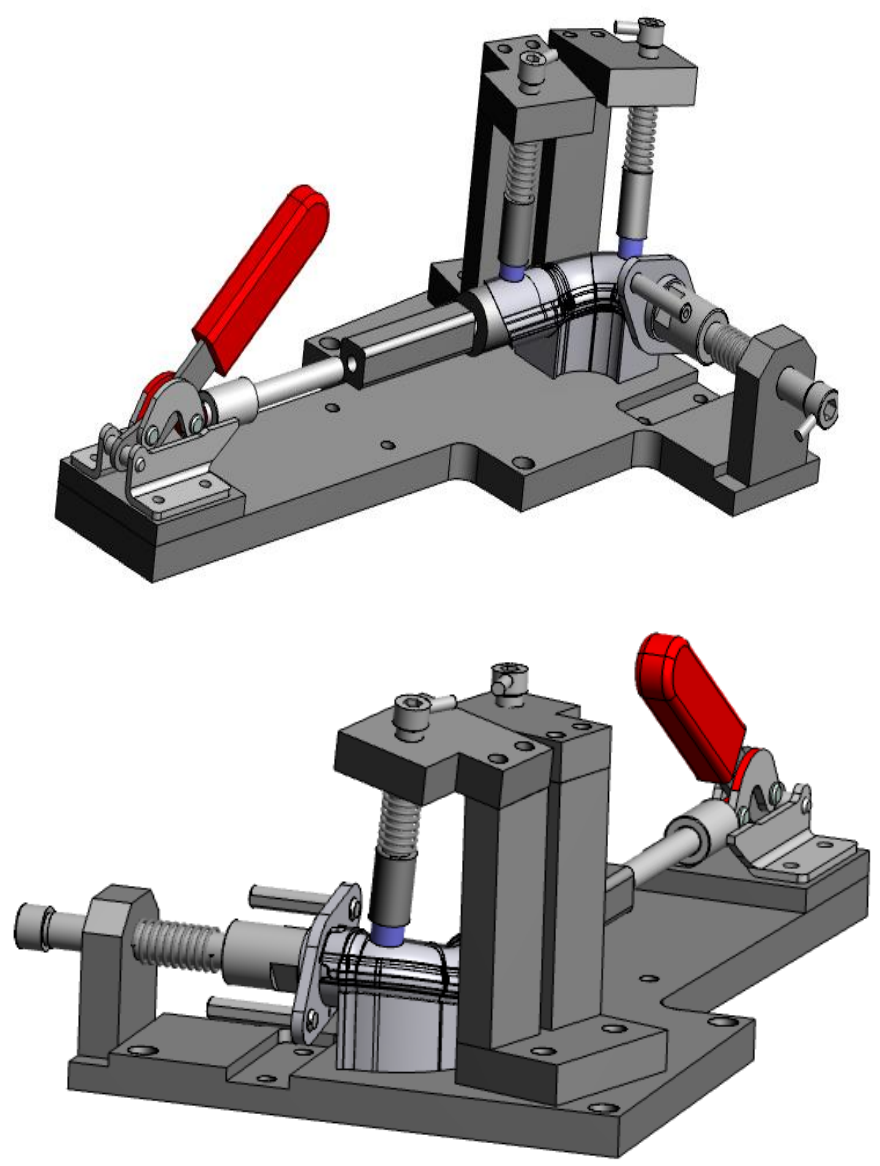

Gambar 4.5 Redesign Jig Half Outer Comp 
Dengan menggunaan jig welding nut (mur) dengan posisi rebah, diharapkan mendapatkan hasil produksi half outer comp yang tidak mempunyai cacat banyak spatter (kotoran las) yang menempel sama sekali, karena posisi dari joint exhaust berada di bagian samping, dengan posisi tersebut diharapkan tidak ada lagi spatter yang menempel pada bagian joint exhaust, seperti pada penggunaan jig welding sebelumnya yang memiliki posisi penempatan tegak.

Penahan spatter dibuat sesuai ukuran dan bentuk body half outer comp atau half $A / B$ yang memiliki diameter lingkaran 25,40 $\mathrm{mm}$ seperti pada gambar di bawah ini.
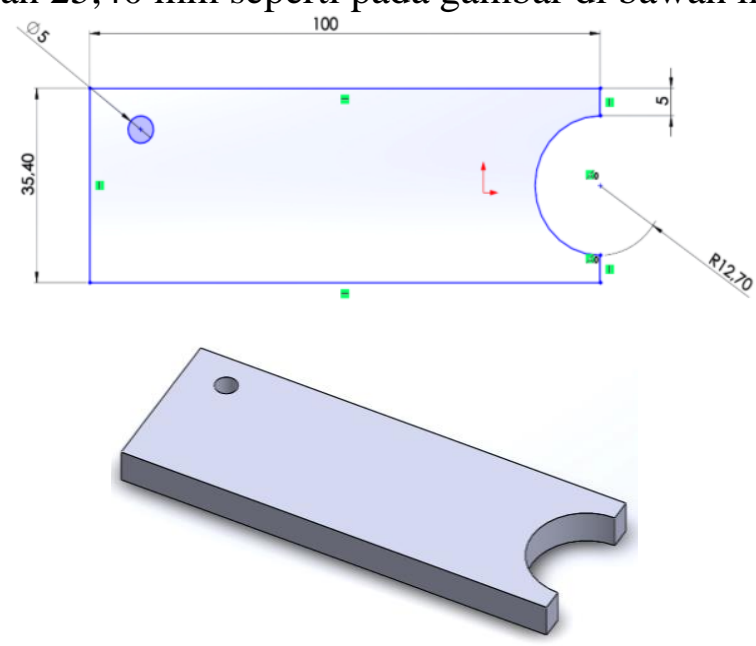

Gambar 4.6 Rancangan Penahan Spatter

Bahan yang digunakan untuk membuat penahan ini adalah bahan tembaga, bahan ini dipilih karena tembaga tidak bisa diwelding, karena konsep mengelas itu adalah mencairkan logam dan menyatukan logam dengan logam lainnya.

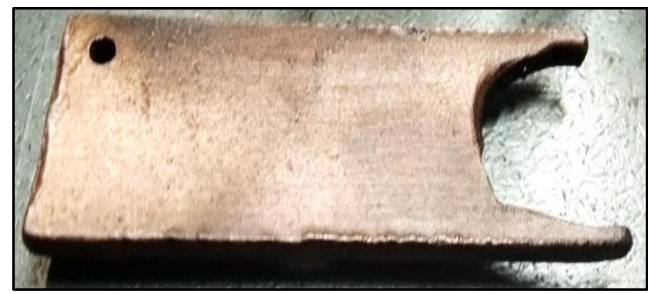

Gambar 4.7 Hasil Penahan Spatter

Pemasangan penahan spatter ini yaitu dengan memasukan penahan ke bagian bawah body half outer comp.

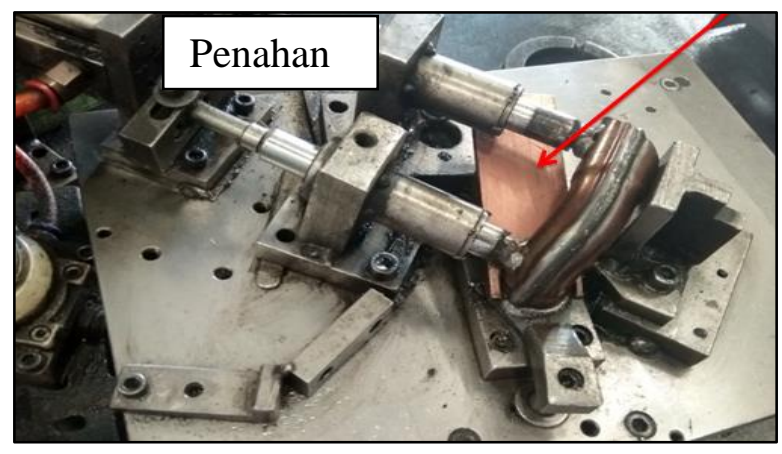

Gambar 4.8 Pemasangan Penahan Spatter 
Improve yang kedua yaitu mengganti clamp jig (penjepit) yang sudah tipis dengan yang lebih besar.
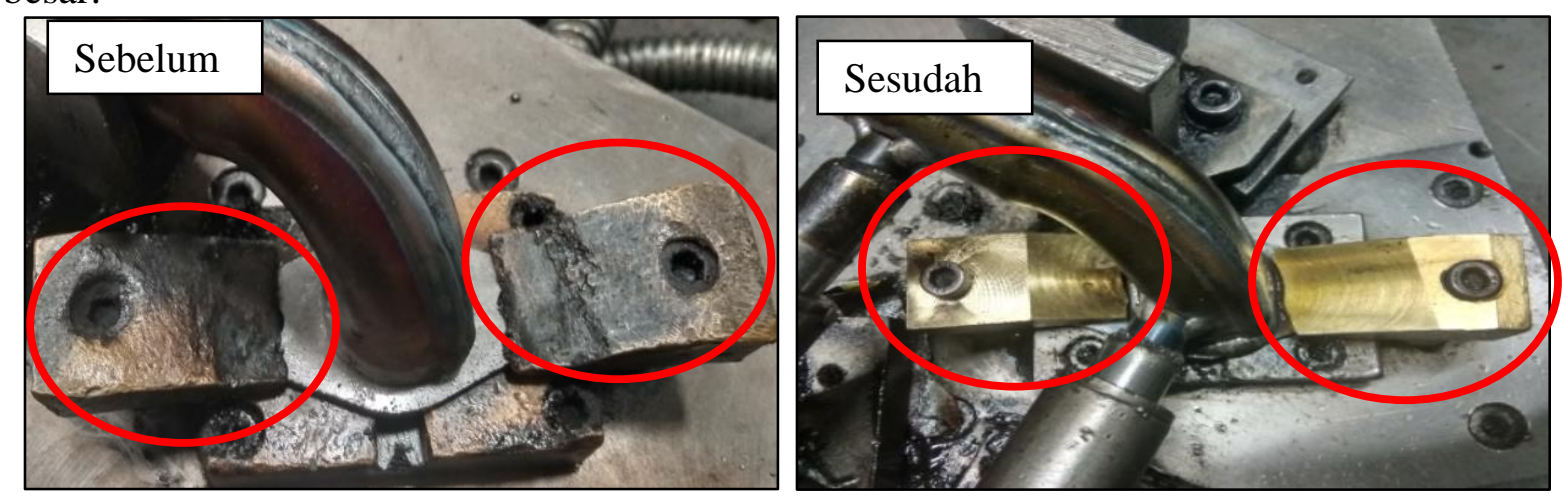

Gambar 4.9 Clamp Jig

Setelah dilakukan improve pada proses welding pemasangan nut (mur) diperoleh hasil berkurangnya jumlah spatter yang menempel pada joint exhaust.
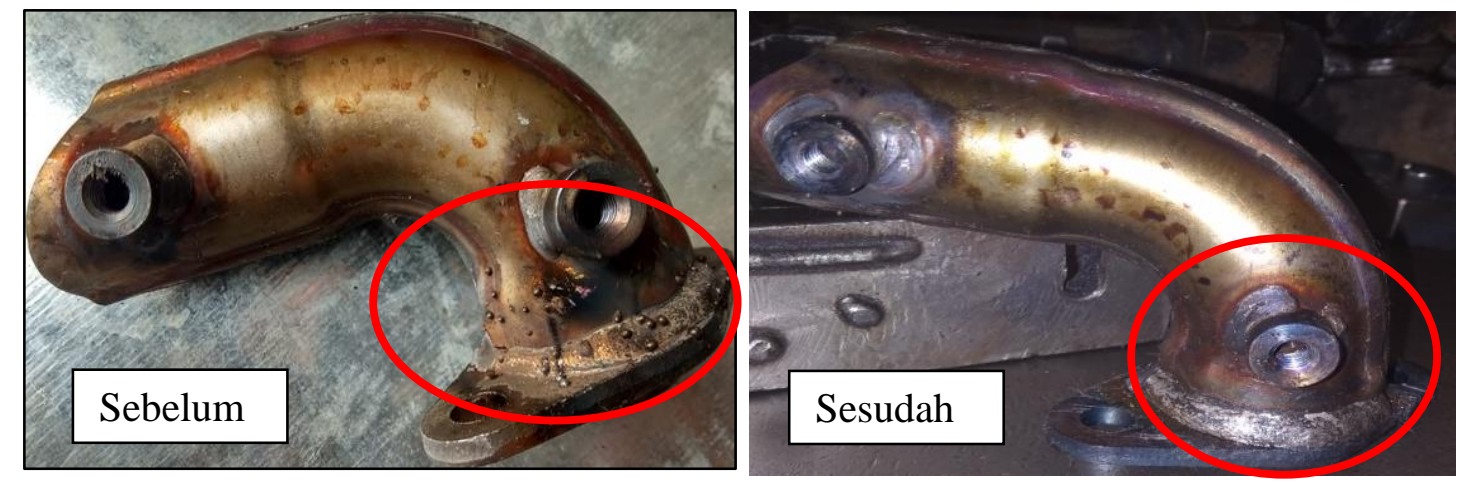

Gambar 4.10 Hasil Improve

Tabel 4.2 Hasil Setelah Perbaikan

\begin{tabular}{|c|c|c|c|c|c|}
\hline Shift & $\begin{array}{c}\text { Target } \\
\text { (pcs) }\end{array}$ & $\begin{array}{c}\text { Hasil } \\
\text { Pengecekan } \\
\text { (pcs) }\end{array}$ & $\begin{array}{c}\text { Jenis } \\
\text { Cacat }\end{array}$ & $\begin{array}{c}\text { Persentasi } \\
(\%)\end{array}$ & Keterangan \\
\hline 1 & 600 & 500 & $\begin{array}{c}\text { Banyak } \\
\text { Spatter }\end{array}$ & $83,33 \%$ & $\begin{array}{c}\text { Pengecekan Sambil } \\
\text { Buang Spatter }\end{array}$ \\
\hline 2 & 600 & 500 & $\begin{array}{c}\text { Banyak } \\
\text { Spatter }\end{array}$ & $83,33 \%$ & $\begin{array}{c}\text { Pengecekan Sambil } \\
\text { Buang Spatter }\end{array}$ \\
\hline
\end{tabular}

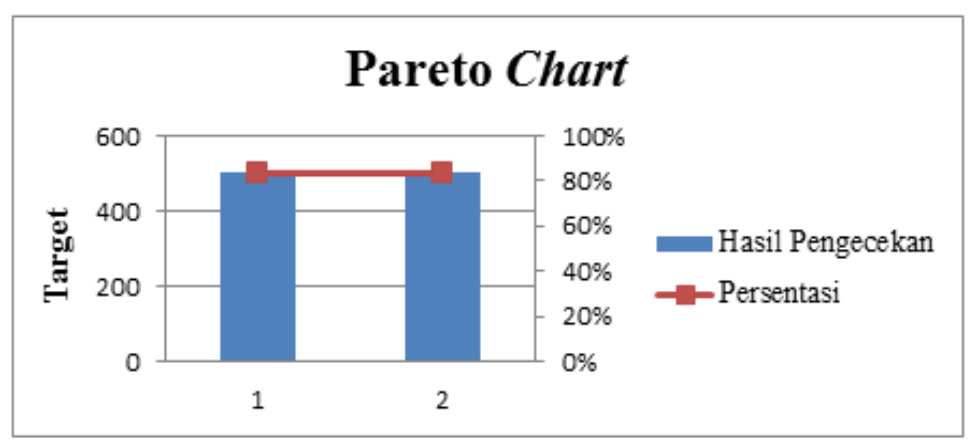

Gambar 4.11 Diagram Pareto Setelah Perbaikan

\section{KESIMPULAN DAN SARAN}




\subsection{Kesimpulan}

1. Spatter (kotoran las) yang menempel diakibatkan oleh proses pemasangan nut dimana jig yang digunakan memiliki posisi jig welding dengan penempatan berposisi vertikal dan juga kondisi clamp jig yang sudah tipis.

2. Spatter (kotoran las) yang menempel menjadi berkurang setelah dilakukan pemasangan Jig dengan posisi horizontal.

3. Perbaikan dilakukan dengan membuat penahan spatter (kotoran las) dan mengganti clamp jig (pengunci) dengan ukuran yang lebih besar.

4. Setelah dilakukan perancangan ulang dan mengubah posisi Jig, memberikan penahan tambahan dan mengganti Clamp Jig yang lama meningkatkan produktivitas sbelumnya $58,33 \%$ menjadi $83,33 \%$.

\subsection{Saran}

Dari hasil improvement diatas masih terdapat Spatter dalam jumlah kecil, penulis menyarankan setiap sebelum melakukan proses pengelasan dapat dilakukan penyemprotan cairan anti Spatter pada Joint Exhaust sehingga pada saat pembersihan tidak terlalu sulit dan tidak merusak produk.

\section{DAFTAR PUSTAKA}

Ariani, (2014). Pengendalian Kualitas Statistik (Pendekatan Kuantitatif dalam Manajemen Kualitas). Jakarta: Andi.

Assauri, Sofjan. (2008). Manajemen Produksi dan Operasi, Edisi Revisi. Jakarta : Fakultas Ekonomi Universitas Indonesia.

Ayudya Mahendaringraty., I Gede Asta Wido Herawan. (2017). Implementasi Dmaic Sixsigma Dalam Meningkatkan Layanan Puskesmas X di Kota Malang. Jurnal Rekayasa Sistem Industri. Volume 3. Program Studi Teknik Elektro. Universitas Ganjayana. Malang., Program Studi Teknik Industri. Universitas Putera Batam. Batam

Gaspersz, Vincent, (2007). Lean Six Sigma for Manufacturing and Service Industries, Jakarta: PT. Gramedia Pustaka Utama.

Hanky Fransiscus., Cynthia Prithadevi Juworo., Isabelle Sarah Astari. (2014). Implementasi Metode Six Sigma DMAIC Untuk Mengurangi Paint Bucket Cacat di PT X. Jurnal Rekayasa Sistem Industri. Volume 3 no. 2. Fakultas Teknologi Industri. Jurusan Teknik Industri. Universitas Katolik Parahyangan. Bandung.

Heizer, Jay dan Barry Render. (2009). Manajemen Operasi Buku 1 Edisi 9. Jakarta : Salemba 4.

Nugroho, Amien. (2009). Ensilkopedia Otomotif. Jakarta : Gramedia Pustaka Utama.

Siswanto. 2011. Konsep Dasar Teknik Las (Teori dan Praktik). Jakarta : P.T. Prestasi Pustakarya. 
Tampubolon, Manahan P. (2014). Manajemen Operasi \& Rantai Pemasok (Operation and Supply-chain Management). (edisi pertama). Jakarta: Mitra Wacana Media

Tannady, Hendy. (2015). Pengendalian Kualitas. Yogyakarta : Graha Ilmu. 